\title{
ADDRESSING THE NOTION OF SOCIO-CULTURAL CONTINUUM SEEN THROUGH THE CHORAL ART AS IT DEVELOPED THROUGHOUT INDEPENDENCE OF UKRAINE: LITERATURE REVIEW
}

Oleksandr M. Marach ${ }^{1^{*}}$, Svitlana L. Panasyuk ${ }^{2}$, Mariia I. Shurdak ${ }^{3}$, Tatyana A. Krivitska ${ }^{4}$, Karyna R. Kinder ${ }^{5}$

${ }^{1 *, 2,3}$ Department of History, Theory of Arts and Performing, Lesya Ukrainka Eastern European National University, Lutsk, Ukraine; ${ }^{4}$ Department of Music and Practical Training, Lesya Ukrainka Eastern European National University, Lutsk, Ukraine; ${ }^{5}$ Department of Choreography, Lesya Ukrainka Eastern European National University, Lutsk, Ukraine. Email: "phd.university@yahoo.com

Article History: Received on $9^{\text {th }}$ April 2020, Revised on $10^{\text {th }}$ May 2020, Published on $18^{\text {th }}$ June 2020

\begin{abstract}
Purpose of the study: The purpose of the present study is to specify the notion of socio-cultural continuum seen through the choral art as it developed throughout independence in Ukraine and to identify its main tendencies as drivers of choral art development. In this regard, the research tasks are to investigate the meaning of the concepts of "continuum", "sociocultural continuum," and to identify the main socio-cultural tendencies that, in our opinion, have the most significant influence on the development of choral art.
\end{abstract}

Methodology: This study used a meta-analysis approach to solve the issues raised in the research. Reference sources, peer-reviewed databases like Education Resources Information Centre (ERIC), Scopus, Arts \& Humanities Database, the Choral Scholar (online journal), Google Scholar, together with open-source-published researches and books (published either in Ukrainian or English) were used to obtain the relevant information.

Main findings: It was found, that the socio-cultural continuum in Ukraine of the period of independence emerges as a complex hierarchical system of phenomena characterized by an inextricable link between the Spatio-temporal parameters of human beings, society, and culture.

Applications of this study: Interpreting this concept in relation to the development of choral art as an imaginary model of a single socio-cultural space-time in Ukraine (region) occurring throughout the independence period in all the continuous hierarchical multiplicity of its phenomena related to the functioning of choral art identified several major trends that, in our opinion, were influenced by the intensity and nature of such development. This period, as a transition period characterized by a change in outlook, the revival of previously forbidden traditions, and the emergence of new socio-cultural trends not only intensified the development but also caused several challenges that Ukrainian society faced.

Novelty/Originality of this study: This scientific exploration was an attempt to understand the theoretical essence of this continuum and its tendencies, which in the future will allow knowing more about their positive and negative orientations and ways.

Keywords: Socio-cultural Continuum, Choral Art, Ukraine, Period of Independence.

\section{INTRODUCTION}

Socio-cultural continuum, which has been functioning in Ukraine for over two decades, is best seen through the choral art. This is due to the fact that the choral art is one of our country's hallmarks in the world cultural space (Ukraine World, 2018) and it displays trends in the artistic processes that take place in modern Ukrainian society during the period of independence and which are caused by several phenomena that create contemporary socio-cultural continuum seen as a continuous space-time multiplicity. These processes are due to (and sometimes contrary to) tendencies that are addressed by a high degree of activity, innovation which go beyond the domestic information space. Though being quite contradictory, those trends need to be considered in the context of the processes that have taken place over the last twenty years in the socio-cultural continuum of Ukraine (Chekan, 2012).

\section{THE RETROSPECTIVE OF THE CHORAL GENRE IN UKRAINE}

It the choral genre, Ukrainian cultural figures created "vertex" artifacts of culture. The long list of those figures varies from Diletsky, Bortniansky, and his contemporaries to the composer's works of today. Moreover, choral culture became one of the most prominent representative activities of Ukraine as an independent state a century ago in the touring activities of Koshits and during the early 1990s, in the work of contemporary collectives under the direction of Avdiyevsky (H. Verovka Ukrainian National Honoured Academic Folk Chorus), Antkiv and Kurach (LevkoRevutsky Men's Chapel), Gobdych (Kyiv Chamber Choir), Bukhonsky and Struts (Khreschatyk Chamber Choir), Savchuk ("Dumka" Choir Chapel), Kulik ("Trembita" Choir Chapel), Vatsek ("Orea" Choir Chapel), Tsyklinsky ("Legenda" Chamber Choir), Yatsyniak (Galician Chamber Choir), Yurchenko ("Renaissance" Chamber Choir), Tarasenko ("Voskresinnia" Chamber Choir), Moisiuk ("Oranta" Chamber Choir), Gazinskiy (Vinnytsia Chamber Choir), Sivohopa ("Hloria" Chamber Choir), and several other well-known leaders of academic choirs. Therefore, to understand the processes taking place in choral art over the last twenty years, it is important to study the socio-cultural continuum as a 
Spatio-temporal phenomenon and trends that influence the development of choral art in Ukraine during the period of independence.

\section{LITERATURE REVIEW}

Different issues related to the development of the contemporary socio-cultural continuum are addressed in many domestic scientific studies, including musicology. Modern researchers are explaining the important positions of their works in the field of modern music and cultural sciences with consideration of the key tenets of the sociology of music by Adorno (2002), Weber (Turley, 2001) as well as the works of Durkheim (Platt, 1995), music studies by Sohor (McAndrew, 2017) and other scholars.

This literature review also relies on the domestic works with the contributors to the "laboratory of the organization of creative processes" at the Kyiv Opera House (in the 1970s) (Kiyanovska et al., 2011). The relevant problems from the perspective of the sociology of culture are also considered in the textbook of Semashko, Pich, and Pogorely (2002) and other sources, the problems of music criticism as a socio-cultural activity are analyzed in details in the textbook by Zinkevich and Chekan(2007) and others.

The review has considered the recent significant works in the field of music sociology performed in Ukraine that revealed the historical, psychological, sociological perspectives of musicology, including a series of studies which analyzed the musical culture and music education through the prism of socio-cultural view of the challenges facing Ukrainian former and leading artists (Kiyanovska et al., 2011). Among those studies, the extensive body of the research of the Kiyanovskaya's School of Musicology in Lviv (Ukraine), the works of Pylatiuk (2006), Shved (2010), Skoryk (2009), Puchko-Kolesnik(2009), Popovich (2002), Zuev(2007) are worth noting, which covered the trends in inculturation, acculturation, didactics in music sociology, as well as the challenges in conductor-choral education, pop, and jazz, festival movement in the contemporary Ukrainian culture, etc.

The above body of cited sources suggests that music sociology is an emerging scientific phenomenon for Ukrainian 'systematic musicology' which studies the forms, the causes for a certain music piece to appear, and it's (music piece's) influence on the relation in the social groups (Kiyanovska et al., 2011). The group of authors distinguished four major groups in the system of concepts of music sociology, which displayed a rather wide range of problems of society. These are as follows:

- General concepts (e.g., musical culture of society, the sphere of musical culture, historical type of musical culture (life), the musical activity of society);

- Concepts related to the objective side of musical life (socio-musical institute, the musical life of society, musical macro- and personal micro-environment, musical needs of society, degree of musical development of society, social functions of music);

- Concepts that relate to the public (the type of music audience, type of listener, audience);

- Concepts related to the public musical perception and consciousness (the musical interests of society, their demands, attitudes, values, tastes, norms, ideals, habits, and traditions) (Kiyanovska et al., 2011).

Therefore, though the subject matter of musical sociology has been specified, the systematization of knowledge in this field is still a matter of the nearer or distant future (Forcini, Maturo\&Ventrec, 2013; Pachucki, Pendergrass \& Lamont, 2007; Sungurtekin, 2009). For this reason, in our scientific exploration, we take into account the plurality of works referred to above ascertain ideas or musical, cultural, and sociological approaches intersect with our views.

The objective of this article is to specify the notion of socio-cultural continuum seen through the choral art as it developed throughout independence in Ukraine and to identify its main tendencies as drivers of choral art development. In this regard, the research tasks are to investigate the meaning of the concepts of "continuum", "socio-cultural continuum" and to identify the main socio-cultural tendencies that, in our opinion, have the most significant influence on the development of choral art.

\section{METHOD}

This study used a meta-analysis approach to respond to the research questions. Reference sources, peer-reviewed databases like Education Resources Information Centre (ERIC), Scopus, Arts \& Humanities Database, the Choral Scholar (online journal), Google Scholar, together with open-source-published researches and books (published either in Ukrainian or English) were used to obtain the relevant information.

The search strategy was based on the key terms like "continuum", "socio-cultural continuum", "choral art" and their cognate terms and combinations. Additionally, the search filters and/or Boolean operators (OR/AND) were used to make the enquires more focused.

The selection procedure included four stages: identification, screening, eligibility, and inclusion. Three reviewers ascertained the eligibility of the studies applying a conceptual framework for critical appraisal developed by Hong and Pluye (2019) and adapted by this research team so that it fitted the objective of the study. 
The 10-grade scale (from 0 (does not fit the scope or standard) to 10 (completely appropriate)) was used to assess the appropriateness of the studies included for this research scope.

The preliminary search found 37 articles, (Ph.D.) researches and books. After screening the abstracts and applying exclusion criteria,9 articles and books were "shortlisted" for the detailed reading because they highlighted the continuum concept (5 sources) and revealed the trends in choral art (4 sources) (see the selection procedure visualized in Figure 1).

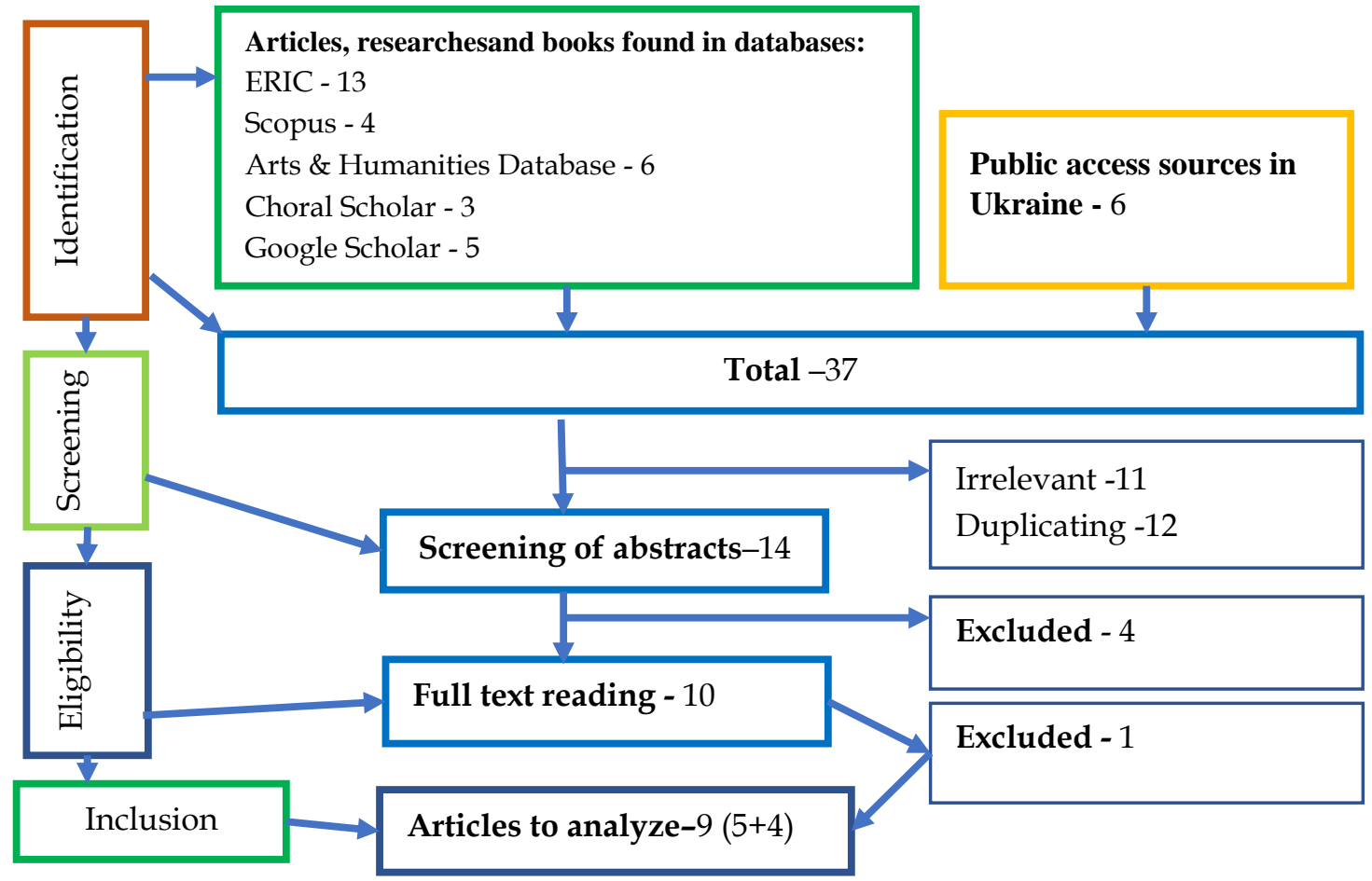

Figure 1: The visualized selection procedure.

\section{RESULTS}

The below-outlined works were studied to specify the notion of the socio-cultural continuum (see Table 1) seen through the choir art as it developed throughout independence in Ukraine and to identify its main tendencies as drivers of choral art development (see Table 2).

Table 1: The outline of works studied to specify the notion of the socio-cultural continuum

\begin{tabular}{|c|c|c|c|c|}
\hline 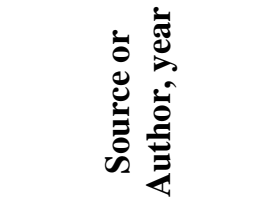 & 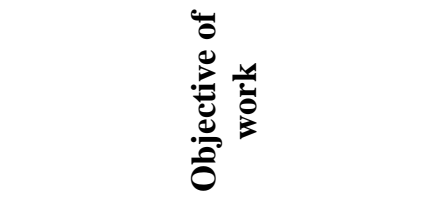 & $\frac{n}{0}$ & $\begin{array}{l}\text { The notion of the socio- } \\
\text { cultural continuum }\end{array}$ & 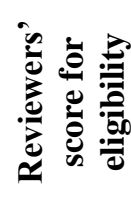 \\
\hline Cohen(2008) & $\begin{array}{l}\text { prove the consistency of the } \\
\text { continuum hypothesis and the } \\
\text { axiom of choice }\end{array}$ & 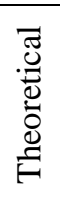 & $\begin{array}{l}\text { a continuous plurality of points } \\
\text { (numbers) }\end{array}$ & 6 \\
\hline$\underline{\text { Svidzinsky(2009) }}$ & $\begin{array}{l}\text { study the relations between } \\
\text { culture and continuum }\end{array}$ & 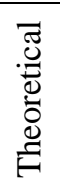 & $\begin{array}{l}\text { related to culture manifested in } \\
\text { the process of self-organization } \\
\text { of the noosphere }\end{array}$ & 7 \\
\hline Drummond (1980) & $\begin{array}{l}\text { work out the notion of a } \\
\text { Guyanese cultural continuum, } \\
\text { which has four characteristics }\end{array}$ & 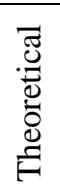 & $\begin{array}{c}\text { cultures are neither structures } \\
\text { nor plural amalgams, but a } \\
\text { continuum or set of } \\
\text { Intersystems }\end{array}$ & 7 \\
\hline
\end{tabular}




\begin{tabular}{|c|c|c|c|c|}
\hline$\frac{\text { McInerney, Walker, }}{\text { and Liem (2011) }}$ & $\begin{array}{l}\text { provide an overview of } \\
\text { theories, methodological } \\
\text { issues and best practices with } \\
\text { the focus on socio-culture }\end{array}$ & $\begin{array}{l}\overline{0} \\
.00 \\
0 \\
0 \\
0\end{array}$ & $\begin{array}{l}\text { interpreted as drivers of human } \\
\text { development and learning }\end{array}$ & 8 \\
\hline
\end{tabular}

Table 2: The outline of works studied to identify its main tendencies as drivers of choral art development in Ukraine

\begin{tabular}{|c|c|c|c|c|}
\hline 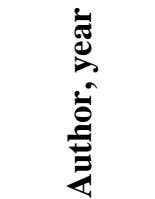 & Objective of work & $\frac{n}{E}$ & $\begin{array}{c}\text { Choral art development } \\
\text { tendencies }\end{array}$ & 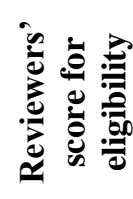 \\
\hline$\frac{\text { Kozak }}{(2009)}$ & $\begin{array}{l}\text { identify the main stages of the formation } \\
\text { of the principles of musical conflict in } \\
\text { the European symphony }\end{array}$ & 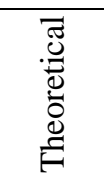 & $\begin{array}{l}\text { "entry" into the European } \\
\text { and music space; } \\
\text { acculturation }\end{array}$ & 6 \\
\hline$\frac{\text { Oleksiuk }}{\underline{(2018)}}$ & reveal music pedagogy in Ukraine & 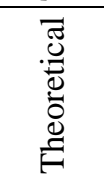 & $\begin{array}{l}\text { inculturation; intensification } \\
\text { of music education; "entry" } \\
\text { into the European and } \\
\text { music space; }\end{array}$ & 8 \\
\hline$\frac{\text { Ornovska }}{\underline{\text { and }}} \frac{\text { Oleksin }}{\underline{(2011)}}$ & $\begin{array}{l}\text { retrospective analysis of the history of } \\
\text { choir development in Ukraine }\end{array}$ & 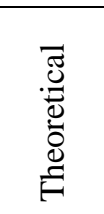 & $\begin{array}{l}\text { Renaissance of religion and } \\
\text { church; inculturation; } \\
\text { institutionalization }\end{array}$ & 8 \\
\hline$\underline{\underline{\text { Shved }}}$ & $\begin{array}{l}\text { study the concepts, functions, tendencies } \\
\text { of the development of international } \\
\text { contemporary music festivals in Ukraine } \\
\text { to improve the Ukrainian festival process }\end{array}$ & 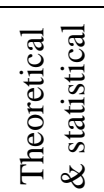 & $\begin{array}{l}\text { inculturation; intensification } \\
\text { of music education; leveling } \\
\text { of musical management. }\end{array}$ & 6 \\
\hline
\end{tabular}

This study also found that physics is closer to understanding the concept of a continuum as being related to sociocultural phenomena. In this science, the term is used to refer to an idealized model of a single physical space-time, which is the result of "identifying points of a geometric continuum with points of physical space-time and defining on a geometric continuum metric relations and functional relationships by imaginary reproduction of solids motion (in classical mechanics) or light signals (in the theory of relativity)" (McInerney, Walker \&Liem, 2011). Distinguishing linear (straight or curve or their segments), two-dimensional (plane or part of it) and, accordingly, three-dimensional continuum, modern physical science has come to understand this concept as a "four-dimensional" Spatio-temporal continuum "and a set of ordered four-verbs of real numbers the first three of which are the spatial coordinates of any point and the fourth characterizes a certain point in time)" (McInerney, Walker \&Liem, 2011).

Besides, Svidzinsky(2004) states that scientific theories emphasize two principles that determine the dynamics of cultural practices that, as we can continue, can be regarded as principles of interaction of elements in the socio-cultural continuum.

The first of them is the concept of the struggle of opposites, which formed the basis of socialist-communist ideology because it justified radical, potent ways of solving problems, and, as the tragic experience of humanity showed, proved to be destructive because it gave rise to criminal practices with enormous numbers of victims.

The second principle is the principle of complementarity, whose idea belongs to Niels Bohr, the concept of this principle offers a completely different understanding of objectively existing opposites: opposites are "able to harmonize lives, not to destroy each other, but to complement, to compensate for the one-sided manifestations that would give rise to each pole of opposites taken separately" (Svidzinsky, 2004).

Therefore, we can logically assume that the process of "harmonization of cultural practices", i.e. the process of their convergence (convergence, interpenetration) in the socio-cultural continuum is based on the principle of complementarity proposed and substantiated by Bohr.

The ideas of understanding the culture described above as a process of self-organization (the synergistic concept of culture) (Svidzinsky, 2004;2009), and relations between cultures on the principle of complementarity, in the projection of musical culture requires an understanding of the musical-historical process offered by the Ukrainian researchers Zinkevich and Chekan (2007), interpreting music history "as a dynamic whole" through the lens of nonlinear sciences. Given the understanding of synergetics described above as a theory of self-organization of systems, which is a nonlinear 
science, Zinkevich's (2009) statement below can be viewed through the prism of synergy itself. So, the musical and historical process is not the sum of "musical facts" (styles, genres, creativity), but a complex dynamic system consisting of multi-tiered stylistic and individual-style trends, clashes of artistic series and multidirectional generic and genre tendencies. In characterizing the process as a multifaceted whole, it is important to emphasize that this concept captures the movement of musical art and integrates other, "small" processes - typological, species, generic, stylistic - that is, what this movement provides" (Zinkevich, 2009). Thus, according to Zinkevich's(2009) interpretation, which can be considered as a synergetic explanation of the essence of the musical and historical process, the latter appears as a complex holistic system in which all components move (causes analogies to complex clock mechanisms), and these components are multilevel style and individual-style trends, generic and genre trends. Such a vivid picture of the essence of the musical and historical process makes it possible to imagine the mechanism of interaction of phenomena in the socio-cultural continuum, where the above trends and tendencies "pass" from one system to another, thus bringing the two systems closer together, and these systems, respectively, acquire genre-style features of each other.

Therefore, we found that the essence of culture as a continuum, which is a complex hierarchical space-time system, whose multiple phenomena are at different levels of self-organization. These considerations directly infer the notion of a "socio-cultural continuum", which is key to this study.

\section{DISCUSSION}

Seeking to specify the notion of socio-cultural continuum seen through the choral art as it developed throughout independence in Ukraine, we propose that the concept of "socio-cultural continuum" is interpreted as an imaginary model of a single socio-cultural space-time in all the continuous hierarchical multiplicity of its phenomena. Taking into account the delineation of the borders of Ukraine (region) occurring throughout the independence period and the connection with choral art, in the context of our work, we interpret the "socio-cultural continuum of Ukraine (region) of the period of independence" as follows: an imaginary model of a single socio-cultural space-time in Ukraine (region) of the period of independence in all the continuous hierarchical multiplicity of its phenomena related to the functioning of choral art. In our opinion, this interpretation is a reflection of the idea of inseparable connection of the mere-trench-time parameters of being human, society, and culture.

Turning to the issue of the development of choral art in the settings of the socio-cultural continuum of Ukraine occurring during the period of independence, it was discovered that the process of development could be regarded as multidimensional and sometimes contradictory. Thus, in the economically difficult years of the late 1980s and early 1990s, a remarkable outbreak of choral art development was observed. Most modern chamber choirs were founded during this period of "national romanticism" and "renaissance of religion and church". Mobile chamber collectives began to represent an independent state on a globalized world cultural continuum and the like. As the experience of communication with many heads of academic choirs of the western region of Ukraine (Kulik, Yatsyniak, Sivohip, Tarasenko, Moisiuk, Gavrilyuk, Tsmur, Demyanets, etc.) (Shved, 2010) shows that the teams encountered problems of enriching the repertoire and its compliance with the needs of the public, but with the avoidance of superfluous simplicity, while maintaining the professional level and so on. With the end of the period of "national romanticism", economic and other problems arose, and new horizons of artistic activity were supposed to emerge.

This study relies on the most significant tendencies of the socio-cultural continuum of Ukraine of the period of independence, which influenced the development of choral art and formed both positive and negative milestones of this development. Those were as follows:

1) The tendency of inculturation as an expression of "national romanticism";

2) The tendency of acculturation as a consequence of the globalization of world society;

3) The tendency to the renaissance of religion and church as factors of cultural development;

4) The tendency of intensification of music education towards its "entry" into the European and world space;

5) The tendency towards the leveling of musical management in the field of academic art and its problematic formation.

Positive appreciation of these tendencies, as shown by artistic practice, depends to a great extent on the leader of the collective as well as their values, artistic aspirations, and their charisma (Sparks, 2019) as a special emotional and psychic features of a person capable of influencing members of the collective united around the head, and his passion (Ferrell, 2015) in the implementation of the goal, the ability to initiate co-activity and collective, and a wider range of people involved in the operation of choral art. This, in our opinion, is the main driver of development in the contemporary socio-cultural continuum. According to Hall (2013), the modern sociological paradigm based on postmodernism "affects views and lifestyles, which in turn determine how an individual fulfills his roles, meets his needs, and grows and adjusts in his different systems".

\section{CONCLUSION}

Therefore, this scientific study was an attempt to understand the theoretical essence of this continuum and its tendencies, which in the future will allow knowing more about their positive and negative orientations and ways. It was found that 
the socio-cultural continuum in Ukraine of the period of independence emerges as a complex hierarchical system of phenomena characterized by an inextricable link between the Spatio-temporal parameters of human beings, society, and culture. Interpreting this concept in relation to the development of choral art as an imaginary model of a single sociocultural space-time in Ukraine (region) occurring throughout independence in all the continuous hierarchical multiplicity of its phenomena related to the functioning of choral art, identified many major trends that, in our opinion was influenced by the intensity and nature of such development. This period, as a transitional period characterized by a change in outlook, the revival of previously forbidden traditions, and the emergence of new socio-cultural trends not only intensified the development but also cause many challenges that our society faced.

\section{THE IMPLICATION OF THE STUDY}

The major practical implication of the study is that it provides much needed empirical data trends, drivers, and impact factors regarding the development of choral art in Ukraine in the independence period.

A second significant implication of the study derives from the finding on principles that determine the dynamics of cultural practices that, as we can continue, can be regarded as principles of interaction of elements in the socio-cultural continuum. The process of convergence (convergence, interpenetration) cultural practices in the socio-cultural continuum is based on the principle of complementarity.

A third implication stems from our reframing of the notion of the essence of culture as a continuum. In the study, it is interpreted as a complex hierarchical space-time system, whose multiple phenomena are at different levels of selforganization.

\section{LIMITATIONS OF THE STUDY AND FUTURE SCOPE OF THE STUDY}

Localized nature and purpose of the research, cultural issues of Ukrainian choral art, and recognition-related issues seem the limitations to this study.

\section{ACKNOWLEDGMENT}

We warmly express gratitude to research team members and all people involved in the automated e-course design so that this study could run smoothly.

\section{AUTHORS' CONTRIBUTION}

All the authors equally contributed to the research at every stage: search, identification, screening, eligibility, and inclusion of the resources.

\section{REFERENCES}

1. Adorno, T. W. (2002). Essays on music. Selected, with the introduction, commentary, and notes by Richard Leppert. The new translation by Susan H. Gillespie. University of California Press.

2. Chekan, Y. (2012). A Millennial Tradition: the Choral Art of Ukraine. http://icb.ifcm.net/en_US/millennialtradition-choral-art-ukraine/

3. Cohen, P. J. (2008). Set Theory and the Continuum Hypothesis. Dover Publications, Inc.

4. Drummond, L. (1980). The Cultural Continuum: A Theory of Intersystems. Man, 15(2), 352-374. https://doi.org/10.2307/2801676

5. Ferrell, M. A. (2015). Choral Conductors and Voice Teachers: Finding Common Ground. The Choral Scholar: TheOnline Journal of the National Collegiate Choral Organisation, 5(1), 30-42.

6. Forcini, S., Maturo, A., \& Ventrec, A. G. S. (2013). The Role of Folk Dance in the Processes of Individual and Social Wellbeing: A Comparison with Other Popular Recreational Activities Through Models of Decision Theory and Game Theory. Procedia - Social and Behavioral Sciences, 84(9), 1750-1756. https://doi.org/10.1016/j.sbspro.2013.07.026

7. Hall, H. (2013). The Impact of Postmodernism on the Social Functioning of Young Adults. Unpublished Dissertation Abstract.The University of Pretoria.

8. Hong, Q. N., \&Pluye, P. (2019). A Conceptual Framework for Critical Appraisal in Systematic Mixed Studies Reviews. Journal of Mixed Method Research, 13(4),446-460. https://doi.org/10.1177/1558689818770058

9. Kiyanovska, L., Lastovetska-Solanskaya, Z., Pilatiuk, O., \&Skoryk, A. (2011). Essays in Musical Sociology: instructional manual. Spolom.

10. Kozak, O. I. (2009). Conflict in Music: Symphonic Inversions in the Socio-Cultural Space: Monograph.Publishing House for Kharkiv State Academy of Culture.

11. McAndrew, S. (2017). Sociology of Music. Sociology. https://doi.org/10.1093/obo/9780199756384-0198

12. McInerney, D. M., Walker, R. A., \&Liem, G. A. (Eds.) (2011). Socio-cultural Theories of Learning and Motivation: Looking Back, Looking Forward (Research on Socio-cultural Influences on Motivation and Learning).Information Age Publishing.

13. Oleksiuk, O. (Ed.) (2018). Professional Artistic Education and Culture within Modern Global Transformations. Cambridge Scholar Publishing. 
14. Ornovska, L., \&Oleksin, H. (2011). Development of Modern Choir Art (To share best practices of "Zorinka" Children's Choral School, Ternopil). Youth and the Market, 10(81), 96-99.

15. Pachucki, M. A., Pendergrass, S., \& Lamont, M. (2007). Boundary processes: Recent theoretical developments and new contributions. Poetics, 35(6), 331-351. https://doi.org/10.1016/j.poetic.2007.10.001

16. Platt, J. (1995). The United States Reception of Durkheim's The Rules of Sociological Method. Sociological Perspectives, 38(1), 77-105. https://doi.org/10.2307/1389263

17. Popovich, O. (2002). Ukrainian Music Life in Przemysl (1919-1999). Unpublished Dissertation Abstract. Lviv State-owned Music Academy named after M. Lysenko.

18. Puchko-Kolesnik, Yu. (2009). The activity of the choir conductor as a socio-cultural phenomenon. Unpublished Dissertation Abstract. Lviv State-owned Music Academy named after M. Lysenko.

19. Pylatiuk, O. (2006). The Original Performance of a Piece of Music as a Phenomenon of the Contemporary Sociocultural Continuum. Unpublished Dissertation Abstract. Lviv State-owned Music Academy named after M. Lysenko.

20. Semashko, O. M., Pich, V. M., \& Pogorely, O. I. (2002). Sociology of Culture: Manual. Caravella Publisher.

21. Shved, M. (2010). Trends in the development of international contemporary music festivals: Monograph. Spolom.

22. Skoryk, A. (2009). Music Programs Broadcasted through Regional Television in The Information Space of the Contemporaneity (On the Example of Programs of Lviv Television). Unpublished Dissertation Abstract. Lviv State-owned Music Academy named after M. Lysenko.

23. Sparks, T. N. (2019). The Choral Conductor as Bard in Motion. The Choral Scholar: TheOnline Journal of the National Collegiate Choral Organisation, 8(1), 17-29.

24. Sungurtekin, M. (2009). The historical evolution of music education and position today in T.R.N.C. Procedia Social and Behavioral Sciences, 1(1), 1899-1904. https://doi.org/10.1016/j.sbspro.2009.01.334

25. Svidzinsky, A. (2004). Can different cultural practices be harmonized? State-Building: An Independent SocioPolitical Journal, 4(6), 2-17.

26. Svidzinsky, A. (2009). The Synergetic Concept of Culture. Volyn Regional Publishing House.

27. Turley, A. C. (2001). Max Weber and the Sociology of Music.Sociological Forum, 16(4),633-653. https://doi.org/10.1023/A:1012833928688

28. Ukraine World. (2018).10 Reasons Why Ukrainian Music is a World-Class Phenomenon. https://ukraineworld.org/articles/ukraine-explained/10-reasons-why-ukrainian-music-world-class-phenomenon

29. Zinkevich, A. (2009). The Logic of the Artistic Process as a Historical and Methodological Problem. Stavropigian Philosophical Studies: Collection of Scientific Papers, 3, 45-55.

30. Zinkevich, O. S., \&Chekan, Yu. (2007). The Musical Criticize. Theory and Methodology: Instructional Manual.Knygy - XXI Publisher.

31. Zuev, S. (2007). Modern Cultural Space and Semiotics of Music Festival (based on best practice in Kharkiv). Unpublished Dissertation Abstract. Kharkiv State Academy of Culture. 